\title{
ON PROPER GENERIC CONCEPTS.
}

By Charles H. T. Townsend.

If any excuse be needed for presenting this subject, it is that we are face to face with the problem of adequate and practical generic concepts in the muscoid flies, and it is a patent fact that the soundness of our taxonomic system depends upon its correct solution.

In approaching this problem it is important to review briefly the work of former systematists, in order to guard against a repetition of their errors. The genera of Meigen's predecessors correspond roughly to our families and subfamilies, those of Meigen to our subfamilies and tribes. These authors do not, therefore, figure in this consideration. We may group subsequent authors as specialists and generalists.

Desvoidy was the first muscoid specialist. He had a close eye for differences, but often showed poor judgment in estimating the value of those differences. No one has ever accused him of confusing distinct forms under one name. His errors lay in attaching too great importance to minor characters subject to variation in the case of species, and in choosing insecure and invalid characters for some of his genera.

Rondani was the next specialist in this group. Although in a sense a general dipterist, he possessed a very special knowledge of the Muscoidea. He, however, misidentified various species of the early authors, due perhaps in large measure to a revulsion of feeling prevailing in his time against the too minute and often misjudged discriminations of Desvoidy. With regard to genera, he revised and extended Desvoidy's system, and his mistakes here are not conspicuous.

Finally Brauer and Bergenstamm, and especially Brauer, abundantly won the honors as specialists in external muscoid characters, and they accomplished this by an intensive study of the external adult anatomy, which led naturally to restricted genera and groups. The only blame that can attach to them is in their ignoring Desvoidy's Myodaires and designating certain invalid genotypes. As intensive students of external characters, it is instructive to note how closely they approached the truth in the majority of their generic and group concepts. Those 
cases in which they confused distinct genera or referred them to wrong groups were due to no fault of perception, but rather to the fact that they had no sure guide to the value of certain slight but constant external adult characters. At the present day we are fortunate to possess such guide in the male and female reproductive system, egg and first-stage maggot characters.

The errors of the specialists are, on the whole, comparatively few and not appalling; while, the causes thereof being recognized, their repetition may be avoided. All favored closely restricted generic concepts.

Let us now turn to the muscoid work of those general dipterists who have passed into history. All of these employed broad as opposed to restricted generic concepts. Macquart, Schiner and Wulp are very important and significant in this connection. Walker, Bigot and Coquillett stand more or less apart from them, but are even more significant. None of these authors can claim the title of muscoid specialist.

The generalists attempted to apply the same broad generic concepts to the Muscoidea that they applied to the rest of the Diptera. Without going into lengthy detail, it is enough to state that their mistakes are many and often overshadow the good contained in their results. Their misidentifications of species are extremely numerous. Their wholesale confusion of distinct generic forms was the natural result of no concise generic concepts. Almost throughout, their genera are mixedgenera. They may be said to have practically lacked muscoid generic concepts, for their generic rulings were largely arbitrary and so loose as to admit numerous foreign elements. The true explanation of all this is that they possessed only the most superficial knowledge of their subject. I wish to add that these statements can be fully substantiated.

History, therefore, testifies to the necessity for restricted generic concepts in the Muscoidea. After many years of intensive study of these flies, I can see this necessity more clearly every day. There is no question whatever of the necessity, either in theory or in practice, but I seek to present some tangible and specific reasons in demonstration.

Investigation of this subject demands consideration of several principles, namely, phylogenetic orientation, environmental adaptation including habitus-convergence, inheritance 
including evolutional trend or anatomical convergence and parallelism, valuation of characters.

In other words, in attempting to fix the proper generic concept in a given group, we must consider the position of that group in the phylogenetic scale (orientation); the response of that group to the factors of the environment (adaptation); and the comparative importance of the various internal and external anatomical structures of all instars for indicating relationships and lines of development both within and without that group (inheritance and valuation). The detailed consideration of these principles leads us to the following reasons for restricted genera in most of the muscoid groups.

(1). Smaller generic value in young stocks owing to greater approximation of the generic stems and their branches, carrying with it the necessity for generic recognition of such stems or types of development from a direct but rather remote common origin, in order to avoid indefinite diagnoses and secure concise generic concepts. Here the principle of orientation figures. The majority of muscoid stocks stand near the limits of present arthropod specialization. They represent the numerous twigs of the phylogenetic tree. As such they are, on the whole, young stocks yet in process of evolution, still approaching their maturity, full of transitionals. These stocks exhibit, each within itself, certain definite lines of development issuing directly from a common source and marking generic stems, which are often connected by transitional species. Groups of generic stems that happen to be connected throughout by transitional species can not be treated as a single genus, on account of their diverse combinations of characters. Such stems must be separately recognized. They can be satisfactorily defined as genera by employing atavic and subatavic characters, or those afforded by structures not especially subject to adaptation. Here the principle of adaptation enters. We have now to provide for the taxonomic disposal of the transitional species. They may be defined as lettered but unnamed subgenera of those restricted genera in common with which they show the most characters of phylogenetic importance. Older stocks do not exhibit such conditions as obtain here. Their generic stems are farther apart, the branches therefrom less numerous, and many of their transitionals have disappeared. (See diagram). 
(2). Necessity for generic separation of cases of parallel or convergent development from what are practically remote or very remote distinct origins; that is to say, anatomical parallelism or convergence in generic stems whose distinctness carries far back into the past, but which are in reality of ancient or very ancient though indirect common origin. Here the principles of inheritance and valuation are paramount. Here, if our generic concepts be not very closely drawn, they will allow the entrance of forms which we know positively to belong outside. The reproductive and early-stage characters serve us especially in this connection as a key to the value of the external adult characters. It is understood that a taxonomic system must neither obscure nor do violence to known relationships or lines of development, but must rather present a true phylogenetic picture. (See diagram).

\begin{tabular}{|c|c|c|c|}
\hline \multicolumn{2}{|c|}{ UNRESTRICTED } & \multicolumn{2}{|c|}{ REstRICtED } \\
\hline PROFIT & LOSS & I'ROFIT & Loss \\
\hline $\begin{array}{l}\text { Transitional spe- } \\
\text { cies are easily re- } \\
\text { ferred generically }\end{array}$ & $\begin{array}{l}\text { But the extremes } \\
\text { of the genus are } \\
\text { too dissimilar to } \\
\text { be included in an } \\
\text { intelligible generic } \\
\text { definition }\end{array}$ & $\begin{array}{l}\text { An intelligible gen- } \\
\text { eric definition may } \\
\text { be drawn up easily } \\
\text { owing to the less } \\
\text { number of forms } \\
\text { included }\end{array}$ & $\begin{array}{l}\text { But transitional } \\
\text { species must be } \\
\text { referred as lettered } \\
\text { subgenera }\end{array}$ \\
\hline $\begin{array}{l}\text { A small number of } \\
\text { generic names is } \\
\text { required }\end{array}$ & $\begin{array}{l}\text { But a generic name } \\
\text { carries no concrete } \\
\text { concept of type, } \\
\text { being instead an } \\
\text { abstract of dissim- } \\
\text { ilar forms, from } \\
\text { which it results } \\
\text { that generic com- } \\
\text { parisons lose their } \\
\text { value }\end{array}$ & $\begin{array}{l}\text { A generic name } \\
\text { always implies a } \\
\text { concrete concept, } \\
\text { securing lucidity in } \\
\text { generic comparison }\end{array}$ & $\begin{array}{l}\text { But a large num- } \\
\text { ber of generic } \\
\text { names is required }\end{array}$ \\
\hline $\begin{array}{l}\text { Correlation of the } \\
\text { reproductive and } \\
\text { early-stage char- } \\
\text { ters with the ex- } \\
\text { ternal adult char- } \\
\text { ters is not required }\end{array}$ & $\begin{array}{l}\text { But the true rela- } \\
\text { tionships and phy- } \\
\text { logeny of the forms } \\
\text { are obscured and } \\
\text { evolutional pro- } \\
\text { cesses ignored, re- } \\
\text { sulting in mixed- } \\
\text { genera and mis- } \\
\text { identifications }\end{array}$ & $\begin{array}{l}\text { Relationships and } \\
\text { phylogenetic lines } \\
\text { are clearly ex- } \\
\text { pressed and evolu- } \\
\text { tional processes re- } \\
\text { cognized, avoiding } \\
\text { mixed-genera and } \\
\text { misidentifications }\end{array}$ & $\begin{array}{l}\text { But reproductive } \\
\text { and early-stage } \\
\text { characters are re- } \\
\text { quired as a key to } \\
\text { the phylogenetic } \\
\text { value of the exter- } \\
\text { nal adult charac- } \\
\text { ters }\end{array}$ \\
\hline
\end{tabular}




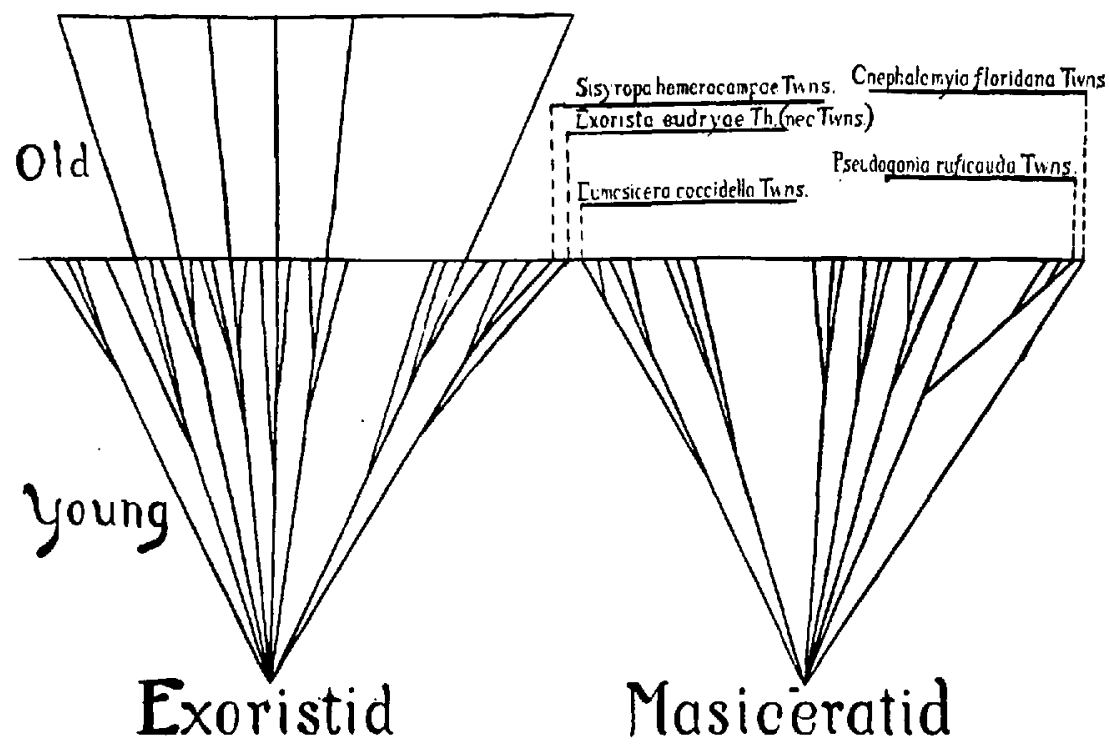

\section{Explaxation OF DIAGRAM.}

The diverging lines from the two common points represent generic stems including typical species or those of same general type as the stems. Branch lines. from the stems represent atypical or transitional species which must be grouped with those restricted genera in common with which they show a preponderance of important characters.

The portion of diverging lines below horizontal dividing line represents young stocks; the portion above same, old stocks. As stocks age the generic stems bccome farther removed from each other, and transitional species largely drop out.

Cnephalomyia floridana and Pseudogonia ruficauda are generically distinct forms, within the Spallanzaniine tribe, with greatly contrasted egg and first-stage maggot, yet so alike in adult as to be almost indistinguishable. Very slight but constant hear characters separate them, and the early-stage characters show that the value of these slight adult characters is generic.

Eumasicera coccidella is a Masiceratid whose adult is extremely similar in external anatomical characters to the adults of the Exoristids Sisyropa hemerocampa and Exorista eudryce Thompson (nec Townsend), yet the first possesses microtype eggs while the others possess elongate sub-cylindrical macrotype eggs with short pedicel. All would be referred to same genus on external adult characters, but the small differences in latter are shown by the early stages to be of family value.

While the diagram might be taken to indicate convergence in the adults in these two cases, it is intended merely to illustrate the close similarity in external adult characters of forms shown by early stages to be ver; distinct. The actual descent has probably been through adult parallelism in both these cases, with juvenile divergence in the Spallanzaniine case, and juvenile-reproductive divergence in the Masiceratid-Exoristid case. 
In summing up the evidence, we may present a contrasted statement showing the advantages and disadvantages respectively of employing unrestricted and restricted genera in the Muscoidea. One method must be right and the other wrong. The right method must show advantages unequaled by the wrong method. It becomes a question of balancing profit and loss in the two methods.

The profit in the unrestricted-genus method is seen to be purely nominal; while the loss is manifestly irreparable. In the last analysis the profit turns to loss. On the contrary the profit in the restricted-genus method is of the greatest practical value; while the loss, to say the most, is easily borne. In the last analysis the loss becomes a gain.

In conclusion I would emphasize one fact. The muscoid flies require the nicest and most delicate taxonomic manipulation. The correct separation of their genera and species requires the most painstaking discrimination. Any tendency to lump forms among them is sure to result in bungling and error. An intensive study of the whole superfamily is urgently needed to correct the multitudinous mistakes of former authors, especially those that we have classed above as generalists. Until one has penetrated deeply into the subject, he cannot begin to rualize the great number of egregious blunders that have been perpetrated by the generalists in this group. Unless one investigates the subject intensively and impartially, he will be unable to realize the conditions. 